\title{
Ex-voto: herança cultural portuguesa no século XVIII em Minas
}

cesar augusto perillo fernandes

\author{
"Je donne à mon espoir mon coeur en ex-voto" \\ GUILLAUME APOLLINAIRE
}

\section{INTRODUÇAO}

Neste trabalho, temos por objetivo fazer algumas considerações sobre 0 ex-voto como herança cultural portuguesa em Minas setecentista. De início, faz-se necessário explicar o que seja o ex-voto, sua origem e importância documental para estudos de natureza sociológica, histórica e filológica. Em seguida, trataremos de seu surgimento e desenvolvimento em Portugal e Minas Gerais.

\section{O EX-VOTO}

\subsection{Definição}

Getúlio César ${ }^{1}$, em seu livro Crendices, suas origens e classificação, dá-nos a etimologia do vocábulo: "Ex-voto, do latim votum, coisa prometida, ou votivus, prometido por voto.". Entretanto, para definir o que seja o ex-voto, recorramos primeiramente a Alceu Maynard Araújo 2, que nos dá uma definição objetiva e pre- 
cisa: "Ex-voto é portanto um quadro, imagem, desenho, escultura, fotografia, peça de roupa, jóia, fita, mecha de cabelo, etc., que se oferece e se expõem nas capelas, igrejas e salas de milagres em regozijo de uma graça alcançada. O nosso caipira paulista chama o ex-voto de promessa ou como diz no seu linguajar peculiar "premessa".".

Alguns autores consideram o ex-voto uma forma distorcida de religiosidade. Dentre estes, Getúlio César chega a dizer que o devocionismo é "... uma religiosidade exagerada, defeituosa...", “... uma maneira defeituosa de crer.". Afirma ainda que o devoto ao "... exagerar excessivamente a sua fé torna-se crendeiro, porque passa a acreditar em tolices, em rezas fortes, prendendo-se na teia de dúvidas por ele mesmo urdida.".

Na verdade, nem todos os autores têm a mesma opinião. Além disso, se formos pensar nas milhares de oferendas que encontramos espalhadas pelos altares, veremos que essa maneira "defeituosa" de crer já aliviou a dor de muita gente. Lá estão os inúmeros ex-votos para testemunhar isso. Não pretendemos aqui questionar a fé, o devocionismo e a crença pura, mas sim analisar o objeto e veículo através do qual as pessoas se expressam, primitiva e espontaneamente.

Sendo assim, passemos a outros autores que manifestam uma opinião mais coerente, objetiva e científica do fato. Souza Barros ${ }^{3}$, em sua obra Arte, folclore, subdesenvolvimento, relaciona o ex-voto aos cultos tabuísticos afro-brasileiros: "O ex-voto seria, em certos casos, uma consagração tabuística, uma forma de fixar a ansiedade causada pela frustração das doenças e, principalmente, com o desejo ou o sentido de imobilizar os seus efeitos ou de evitar a sua volta.". Guimarães Rosa 4 registrou, em seu conto São Marcos, manifestações de magia negra ocorridas - e que provavelmente ainda ocorrem - no sertão mineiro, relacionando-as ao ex-voto: "Precipitei-me, porém, para ver o que o negro queria esconder atrás do jirau: um boneco, bruxa de pano, espécie de ex-voto, grosseiro manipanço.".

Já outro autor, Raimundo Dall'Agnol 5, vê no ex-voto uma forma de comunicação bastante abrangente: "O ex-voto é uma forma de comunicação. Em primeiro lugar estabelece a ligação 
subjetiva e sacral do devoto com a divindade; um feed-back consciente aos céus por ter sido atendido na súplica que abriu o dílogo com o "santo" invocado. Em seguida, é uma expressão de comunicação de massa, tornando público o favor obtido através de um veículo de massa médio. Isto se verifica pela oferta de um produto artesanal ostensivo, constitutivo do ex-voto, ou na divulgação da "graça alcançada" pelas colunas de jornais.".

Lélia Coelho Frota ${ }^{6}$ realça que o ex-voto testemunha “... a reciprocidade de dons trocados entre o humano e o divino, no plano da organização religiosa. Através de ação corporal e/ou oferta material, o indivíduo agradece à entidade sobrenatural que o acudiu em momento de vicissitude o benefício recebido.".

Maria Augusta M. da Silva ?, em excelente estudo sobre os ex-votos brasileiros, faz uma distinção entre voto e ex-voto: "O voto se caracteriza como ato propiciatório anterior à graça ou mercê desejada ou, simplesmente, dirigido à divindade (ou seus agentes), como tributo de fé, ou de reverência e vassalagem. Ex-voto é a prática desobrigatória posterior à graça ou mercê alcançada, como testemunho público contemporâneo, não só da força milagreira da divindade (ou seus agentes), mas também da gratidão do milagrado.".

Muitos são os estudos que enfocam ou fazem referência aos ex-votos. Dentre eles, temos uma citação em livro de Cecillia Meireles ${ }^{8}$, Artes populares, que busca analisar e discutir a importância das artes populares no Brasil: "Ex-votos são milagres: coisas impossíveis obtidas quando já se não tinha esperança, perigos evitados quando parecia nāo haver mais salvação.".

\subsection{Origem}

Geralmente, os autores que tratam do assunto se referem à antigüidade da prática do ex-voto, associando sua origem a cultos religiosos de tempos muito remotos. Vejamos o que dizem esses autores.

M. Augusta M. da Silva 9 vai relacionar a sua origem à antigüldade clássica: " nada aos lastros culturais greco-romanos. Embora a sua origem 
seja desconhecida, sabe-se que a sua difusão se deu por volta do ano 2.000 A.C. na área do Mediterrâneo Antigo.".

Já Gilka Corrêa de Oliveira ${ }^{10}$, sem precisar uma civilização ou região onde tenham surgido, vai considerar a prática dos ex-votos universal e secular: "A prática dos ex-votos é um fenómeno universal, secular, remonta desde as civilizações mais antigas.".

Oswaldo Meira Trigueiro ${ }^{11}$ também val acrescentar-nos alguma coisa sobre a origem dos ex-votos: "Não podemos determinar a origem e a difusão da prática do ex-voto; sabemos, no entanto, que os povos do antigo Mediterrâneo, há 3.000 A.C., já ofertavam animais, troféus conquistados nas guerras, vestimentas e outras peças aos deuses pagãos pelas vitórias nos campos de batalha.".

Entretanto, quem nos vai fornecer maiores informações sobre a presença dos ex-votos na antigüidade é Getúlio César 12: "O ex-voto era usança difundida nas crenças pagãs reinantes no Egito, Pérsia, Caldéia, Grécia, India, Roma, China e outros paises. Chegou até nossos dias e continua a ser objeto de crença entre cristãos crendeiros, crédulos de várias crenças.

Três mil anos antes de Cristo já se praticava o oferecimento de ex-votos aos deuses pagãos.

Os gregos davam aos ex-votos as denominações de caristeria, sestre e anathmata. Entre os romanos passaram a ser donária de donarium - oferenda, donativo - e tabulae votivae - contrato prometido.

Na velha Babilônia, a cidade mais bela e mais erudita da Caldéia, ex-votos e oferendas votivas eram oferecidos à deusa Gula, a "grande médica", para pagamento de favores recebidos e a receber.

No Império Romano as pessoas que chegavam à puberdade ofereciam ao deus Apolo, colocando-a no seu templo, a cabeleira que conservavam para esse fim.".

De fato, é comum encontrarmos nas epopéias e tragédias gregas referências à prática dos votos e ex-votos - por exemplo, as oferendas votivas na Odisséia, Electra e Hipólito. Vejamos agora o que nos diz Márcia de Moura Castro ${ }^{13}$ sobre a prática. 
votiva na Idade Média e Renascimento: "Durante a Idade Média as práticas religiosas de origem mediterrânea foram um tanto abandonadas, conhecendo-se poucos exemplares de ex-votos pertencentes a esse período em que os povos nórdicos tiveram o domínio do mundo ocidental. As demonstraçōes individuais tornaram-se raras, cedendo lugar às grandes manifestaçōes coletivas de devoção e fé: as cruzadas, as peregrinações aos santuários famosos, como o de Santiago de Compostela, e as grandes procissões propiciatórias.

Com o Renascimento, as nações latinas reassumem a liderança, e, através do novo meio de expressão - a pintura de cavalete - a arte foi de novo se individualizando.".

Sobre a prática dos ex-votos no Renascimento, temos um interessantíssimo documento e testemunho na grande obra de Erasmo de Roterdam 14, o Elogio da Loucura: "Além desses, existem outros santos que gozam de um crédito e um poder universais, encontrando-se entre estes, em primeiro lugar, a mãe de Deus, a quem o vulgo atribui poder maior que o do seu próprio fillho. Ora, as graças que os homens pedem aos santos nāo serão, talvez, insinuadas também pela Loucura? Dizei-me se, entre tantos votos religiosos de reconhecimento que vedes cobrindo por completo as paredes e as abóbodas das igrejas, já vistes pendurado um único de reconhecimento por cura milagrosa de loucura. Decerto que não: os homens não costumam importunar os santos para obter uma graça dessa natureza. Daí resulta que, por maior que seja a sua devoção, nunca se tornam nem um pouquinho mais sábios. Eis por que, enquanto se vêem, suspensos dos altares, votos relativos a toda sorte de graças recebidas, nenhum se encontra, todavia, que se refira a um caso curado de loucura. Aquele pendurou um voto por se ter salvo a nado quando julgava naufragar; este, porque não morreu de um grave ferimento recebido numa briga; um outro, porque, enquanto os outros caíam prisioneiros do inimigo, conseguiu subtrair-se ao perigo, graças a uma feliz e valorosa fuga; aquele outro, porque, tendo sido condenado à forca como prêmio as suas boas açōes, caiu do laço, graças a algum santo dos larápios, a fim de que, pior do que antes e em virtude da caridade do próximo, voltasse a roubar os que tivessem a bolsa 
muito cheia de dinheiro; um outro por ter recuperado a liberdade rompendo as grades da prisão: outro por se ter restabelecido facilmente de uma febre muito grave, com grande mágoa do médico, que esperava fazer uma cura mais longa e lucrativa; este, porque, em lugar da morte, encontrou remédio no veneno que lhe fora dado, enquanto sua mulher, que já suspirava pelo momento de libertação, ficou na maior amargura por ter falhado o golpe; outro, porque, tendo caído com seu carro, não teve receio algum e pode reconduzir à casa, sãos e salvos, os cavalos; aquele, porque, tendo ficado soterrado num desabamento, conseguiu salvar-se sem nada sofrer; outro, finalmente, porque, tendo sido pillhado em flagrante pelo marido de sua bela, saiu da enrascada com a maior desenvoltura.

Ora, bem vedes que ninguém deu graças a Deus ou a virgem, ou a qualquer santo, por ter recuperado o júzo.".

O que podemos observar nesse trecho é que o autor, na linguagem satírica e picante que the é peculiar, brinca com o tema, como no caso do larápio que fugiu da forca ou do marido que escapou de ser assassinado pela mulher. A alusão feita por Roterdam à preferência dada pelos devotos à mãe de Deus, “... .a quem o vulgo atribui poder maior que o do seu próprio filho.", mostra-nos um comportamento religioso e popular que sobrevive até hoje. Muitos devotos fazem seus pedidos e os agradecem diretamente aos santos ou à Virgem, sob seus diversos títulos, Nossa Senhora da Conceição, das Dores, de Fátima, etc. Entre nós, esse tipo de devoção parece ser mais frequiente que aquela que se tem por Cristo, com a exceção, evidentemente, das regiōes tradicionalmente consagradas à devoção ao Senhor Bom Jesus de Matosinhos, como ocorre na cidade de Congonhas do Campo, MG.

\subsection{Importância documental}

O ex-voto, pela multiplicidade de informações que carrega, constitui fonte histórica documental da maior importancia. Filólogos, antropólogos, sociólogos, historiadores, teólogos e artistas nele encontram um manancial riquíssimo. Vejamos o que alguns estudiosos dizem a respeito. 
G. C. de Oliveira ${ }^{15}$ afirma que: "Os acervos de ex-votos dão a conhecer grande parte dos problemas sociais a serem resolvidos". Isso porque neles estão espelhadas as doenças e, em alguns casos, a miséria e a exploração do homem.

Osvaldo $\mathrm{M}$. Trigueiro ${ }^{16}$ realça o seu múltiplo valor documental: "Além da finalidade principal que tem o ex-voto, como peça para se pagar uma graça alcançada a um santo, há também de se considerar o seu valor antropológico, social, artístico e como veículo de comunicação popular.", "Como documento para um estudo mais profundo da cultura universal, e principalmente a do povo brasileiro, podemos encontrar no ex-voto grande fonte de informação.".

Como fonte de pesquisa lingüistica e filológica, o ex-voto, em sua forma de quadro pintado com legenda, chamado tábua votiva, fornece rico material. Só nele podemos encontrar uma linguagem escrita popular do séc. XVIII. M. Augusta M. da Silva ${ }^{17}$ realça esse aspecto documental dos ex-votos dessa época: "O estudo do linguajar, tanto erudito quanto popular, encontra nessas tábuas de narrativa um fantástico potencial documentário.".

Como objeto artístico, Pietro Maria Bardi 18 chama a nossa atenção para este "... encanto da arte primitiva...", destacando o seu efeito de obra de "imediata comunicação".

Cecilia Meireles ${ }^{19}$ também destaca o valor artístico dos ex-votos escultóricos e pintados. Nesta citação ela fala sobre os últimos: "De igual ingenuidade, porém ricos de composição e expressão, representando um aspecto precioso da pintura popular são os ex-votos que se encontram nas capelas e sacristias, e que traduzem promessas feitas ou graças recebidas.".

Márcio Sampaio ${ }^{20}$, crítíco mineiro de artes plásticas, aproxima o nosso ex-voto das formas espontaneas da arte popular: "A margem da evoluçāo do gosto das camadas cultural e economicamente privilegiadas vamos encontrar a manigestação espontânea e atemporal de uma arte popular, de caráter religioso, onde se pode perceber uma relação mais pura do homem com a natureza.". 
Hanna Levy ${ }^{21}$, em importante estudo publicado na Revista do Patrimônio Histórico e Artístico Nacional, destaca o papel da tábua votiva na descrição dos ambientes da sociedade colonial. Arquitetura, vestuário, ormamentação, mobiliário, costumes e retratos estão presentes nessas pequenas obras primas da arte primitiva colonial: "Por primitivos que sejam os ex-votos, técnica e artísticamente falando, oferecem entretanto ao observador a representação de um ambiente individual, coisa que nunca se vê nos retratos coloniais. Dado o seu interesse histórico-documental, constituem, pois, valioso elemento complementar dos retratos de sua época.".

Também para 0 artista plástico 0 ex-voto tem despertado 0 interesse. Haja vista as obras de Antônio Maia, pintor que utiliza o ex-voto escultórico como tema para sua pintura, além de Farnese de Andrade, escultor que utiliza as próprias peças votivas em suas esculturas.

Há que se lamentar, entretanto, estarem peças de tamanho interesse documental espalhadas por capelas, antiquários e mãos de colecionadores, dificultando extremamente o trabalho de pesquisadores e estudiosos. O roubo e a venda indiscrimada desses ex-votos exigem, também, dos órgãos responsáveis, um posicionamento que vise defender, proteger, catalogar e agrupar em locais apropriados as peças que, atualmente, se encontram dispersas.

\section{O EX-VOTO EM PORTUGAL}

O ex-voto em Portugal decorreu de uma tradição européia, associada a tempos imemoriáveis da antigüidade. Márcia de Moura Castro 22 levanta, em seu trabalho, algumas formas votivas ibéricas anteriores à prática do pagamento de promessa através da tábua pintada, que só ocorreu com maior expressão no século XVIII: "No políptico de São Vicente, embora ainda coletivo no sentido em que representa todas as parcelas da populaçāo, Nuno Gonçalves conseguiu cristalizar o espirito daquela época em que a vontade do homem mais se afirmou em toda a história da humanidade. Cada individuo expressa ali sua força interior e.o 
espírito pioneiro com que contribuiu para os acontecimentos épicos das Grandes Descobertas. Rei, príncipe, pescadores, clérigos, nobres e povo agradecem ao padroeiro de Lisboa as grandes vitórias no mar e na terra.

D. João II fez-se retratar por Cristóvão Lopes, com São João Batista seu patrono. Num tríptico de autor desconhecido, o jovem infante que viria a ser $D$. João III aparece com seu irmão D. Luis ao lado da Virgem. Por essa mesma época, em toda a Europa esse mesmo costume fol adotado. Os grandes personagens de Espanha, como os Reis Católicos, o Duque de Alba, Cristóvão Colombo e muitos outros, igualmente valeram-se da pintura para demonstrar sua fé e gratidão...".

Lélia Coelho Frota também faz algumas considerações a respeito do ex-voto europeu após o século XV: "Com a disseminação da pintura a óleo a partir do século XV, as dimensões do ex-voto europeu se reduzem, o seu uso se multiplica e o vocabulário visual tende a diferenciar-se, conforme os emitentes pertençam à norma culta ou à popular.".

Márcia de Moura Castro ${ }^{24}$ vai realçar que, com a tábua votiva, "o ex-voto foi deixando aos poucos de ser um privilégio dos grandes para tornar-se uma manifestação popular de exaltação mistica.".

Robert Smith 25 vai levantar aspectos relevantes em seu artigo O caráter da tábua votina luso-brasileira. Primeiramente, temos questōes relativas à origem desses ex-votos em Portugal: "Em Portugal as peças mais antigas datam apenas da segunda metade do século XVII, enquanto na Itália há exemplares que remontam até Quatrocentos. As raras tábuas seiscentistas portuguesas, mal conservadas e de pouco interesse artístico, mostram figuras em camas quase sem indicação de mobilia ou indumentária da época.

No século XVIII foi aumentada a gama de apresentação, figurando muitos tipos de cenas relativas às duas categorias de Desastres e Doenças.". Na primeira categoria, Smith enquadra os ex-votos relativos a "acidentes ocorridos em viagem"; "naufrágios"; "desastres a partir dos que resultam na lavoura e que abrange os roubos, efetuados por assassinos"; além das tábuas votivas que comemoram "os efeitos de raios e terremotos que amea- 
çaram a vida de gente". Na segunda, há, quase sempre, a representação de um "quarto do doente com sua cama e alguns móveis típicos de sua camada social". Os ex-votos dessa categoria representam "...uma fonte valiosa para o estudo da história social e do mobiliário português.". Referindo-se à linguagem expressa na legenda desses ex-votos, Smith acrescenta que... "A extensão da legenda é característica das tábuas votivas relacionadas a doenças, que às vezes fornecem até o nome dos médicos consultados pelos doentes...".

Vejamos agora algumas legendas de ex-votos portugueses transcritos por Smith em seu estudo. Estes dizeres interessarão, em seguida, à confrontação com as tábuas votivas mineiras dos séculos XVIII e XIX, como a legenda deste sugestivo ex-voto de um preso:

"Milagre q fes N.S. da M. em um preso q falsam. te era acusado e recorreu a N.S. e logo foi solto em 1769." 26

Temos também esta outra legenda, relativa à categoria dos desastres, segundo denominação de Smith:

"Milagre que fes N." Senhor dus Desprezos a D. Quiteria Luiza Fernandes e Menezes na noute de 6 para 7 de Agosto de 1836 sendo atacada na sua Quinta de Romil, freg. a de Adão. e por huma grande malta de bandoleiros..." 27

\section{O EX-VOTO EM MINAS GERAIS}

Fm seu trabalho, M. Augusta $M$. da Silva 23 destaca três tipos de ex-votos de origem ibérica transplantados ao Brasil:

- "ermidas e capelas que se ergueram em público testemunho de milagres" - possui valor documental histórico e arquitetônico, como, por exemplo, as igrejas do 0 , em Sabará, e do Bom Jesus de Matosinhos, em Congonhas;

- "desobrigas de voto em donativo e, sobretudo, dádivas de objetos preciosos de propriedade do milagrado ou mandados executar para a oferta de gratidão" - constituem-se em "tesouros de caráter museológico"; 
- "registro pictórico", vinculado às tábuas votivas de Portugal. No Brasil, vai surgir no começo do século XVIII, entrando em declínio só com o advento da fotografia.

A mesma autora realça o papel do colonizador na transmissão de uma cultura vinda desde tempos da antiguiidade clássica: "Com o colonizador português chega ao Brasil o lastro mágico dos grego-romanos, acrescido por condicionamentos peculiares à península ibérica.".

Outros autores reafirmam o papel do português na divulgação do ex-voto em Minas Gerais e no Brasil. G.C. de Oliveira ${ }^{26}$ fala de todo um legado aos nossos costumes religiosos: "Os portugueses introduziram a prática dos ex-votos no Brasil, através da Religião Católica, e nos legaram tamém todas as crendices, rituais, usos e costumes religiosos.".

Lélia Coelho Frota ${ }^{30}$ também identifica a raiz ibérica do nosso ex-voto pintado: "O ex-voto é o sinal visível com que o crente cumpre a promessa feita a determinada divindade, que 0 teria socorrido em momento de vicissitude. No Brasil, fizeram-se tábuas votivas pintadas, no século XVIII e XIX, em Minas Gerais, Bahia e Rio de Janeiro, ligadas à iconografia do ritual católico ibérico. E também os ex-votos, no sertão nordestino, esculpidos em madeira, modelados em barro ou, mais raramente, recortados em metal. Tanto os ex-votos pintados como os esculpidos receberam entre nós o nome de milagres.".

Márcia de Moura Castro ${ }^{31}$ realça a aclimatação do ex-voto aqui: "A pequena tábua votiva teve imensa popularidade em Portugal e de lá transplantou-se para o Brasil, aclimatando-se muito bem em Minas Gerais.".

Embora os dois primeiros tipos de ex-votos descritos por Silva tenham ocorrido até com certa frequiência em Minas Gerais, procuraremos, nesta parte do trabalho, enfocar prioritariamente o terceiro tipo. Isso por ter sido muito comum no século XVIII, além de seu imenso valor documental - como ficou realçado na parte 2.3 deste trabalho - transmitindo-nos um grande número de informações relativas ao setecentos mineiro. 
A tábua pintada mineira é de pequena dimensão e acentuado tom popular. Sobre a técnica com a qual era feita, $M$. de $M$. Castro ${ }^{32}$ afirma que: "Na Colônia como na Metrópole, foi mais usada a pintura a têmpera sobre tábua, de há muito abandonada pelos mestres europeus. O emprego dessa técnica medieval obsoleta ajudou a.difundir o uso do ex-voto, dada a facilidade de obtenção da madeira, enquanto que a tela exige a intervenção de artesãos especializados, sendo por isso usada somente nos raros exemplares eruditos...". A seguir, levanta outras características dos ex-votos mineiros: "As tábuas votivas mineiras, à semelhança das portuguesas, são quase sempre de sabor popular. Nelas foi empregada a mesma técnica, igual disposição de elementos e em sua maioria os mesmos santos são invocados. No primeiro plano destaca-se a figura do pagador da promessa, no seu momento de maior aflição...", 'Podem variar os pequenos detalhes, mas dificilmente faltam ao ex-voto as inscrições que narram as doenças ou acidentes...", "Tampouco falta a imagem milagrosa ao alto, envolta em nuvens azuladas.", "A perspectiva e a ortografia, quase sempre erradas, mostram que a autoria é de um curioso, pintor de ocasiāo que permanece sempre anônimo...", "Como cores dominantes destacam-se o azul e o vermelho...", "Raramente a cena é exterior com paisagem ou casario, embora possa aparecer algum detalhe arquitetônico.".

Lélia Coelho Frota ${ }^{33}$, em análise sobre as tábuas votivas de Congonhas do Campo, recentemente tombadas pela SPHAN e agora conservadas na Sala de Milagres do santuário da mesma cidade, também descreve a tipologia do nosso ex-voto pintado, realçando que a mesma continua tradição da peninsula ibérica: "Verificamos que o ex-voto pintado nos séculos XVIII e XIX em Minas continua a tipologia ibérica, distribuindo-se em três planos: no terço inferior, a legenda com o nome do miraculado e as circunstâncias e data em que ocorreu o milagre; no terço médio, a figura do miraculado em seu quarto, preferencialmente deitado em posição prémortuária; no plano superior, em geral à direita, a representação da divindade propiciadora da graça.". 
Robert Smith ${ }^{34}$. considera o ex-voto mineiro transplantação pura e simples dos moldes portugueses: "A tábua mineira oferece portanto sólidas provas do transporte de um hemisfério para outro não somente do mesmo formulário religioso, como também dos idênticos processos técnicos e artísticos nele manifestados.".

Algumas modificações, entretanto, podem ter ocorrido com as tábuas pintadas na Colônia. O tema pede um profundo estudo comparativo entre ex-votos mineiros e portugueses, antes de aventarmos qualquer hipótese. Cabe lembrar, contudo, que o grande conhecedor de nosso folclore, Luís da Câmara Cascudo ${ }^{36}$, referindo-se aos ex-votos escultóricos, também de origem ibérica, diz que: "A mentalidade brasileira modificou o ex-voto recebido de Portugal em leve mas persistente acentuação local. As figuras de negros e mulatos, ou dos "brancos", deduziveis pelas cabeças oferecidas aos Santos terapêutas, não imitam submissamente os tipos clássicos e nem mesmo os ex-votos estudados na Europa.". O mesmo pode ter ocorrido com o ex-voto pintado, seja na forma, nos temas, nas devoções, etc. Uma coisa parece certa, o nosso meio influiu decididamente na difusão do ex-voto pictórico de origem ibérica. $M$. de M. Castro ${ }^{36}$ lembra que: "Com a eclosão do ciclo do ouro em Minas Gerais, mais do que nunca eram necessárias a fé e a devoção numa terra desconhecida, infestada de selvagens quase sempre hostis, animais, doenças e perigos de toda a espécie, além da inveja, da cobiça e outras paixōes humanas...".

Vejamos agora algumas legendas de ex-votos mineiros do século XVIII. Infelizmente, não nos foi possivel por ora publicá-las juntamente com as reproduções fotográficas. Lembro aqui que buscamos fazer a transcrição seguindo o mais fielmente possível o texto original. Mesmo assim, ao passar para um papel, em letra tipográfica, o ex-voto perde uma de suas maiores originalidades, a interessante e barroca caligrafia. Podemos observar porém, nestas transcrições, a ortografia, os temas, o emprego de vocábulos, etc. Gostaria de lembrar que o nosso interesse por ora é apenas apresentar os textos, deixando para uma próxima oportunidade, talvez no próprio Boletim do CESP, uma análise textual mais profunda dos ex-votos mineiros. 
Primeiramente, vejamos três ex-votos de Minas Gerais nos quais os devotos agradecem por terem escapado de situações constrangedoras. Neles temos as seguintes legendas:

a. "Milagre q. fes $\mathbf{N}$. Snr $\mathbf{r}^{\mathrm{a}}$ da Nazareth por interçeção. das Almas Santas, a Manuel Ribr do ... Santos Sereno: Vindo depedir exmollas das Almas, arecolher $\mathrm{p}^{7}$ caza, the estava ... esperando no caminho hum seu Inimigo, elhe fes dous tiros, ambos empregaraõ com 4 perđigotos na cabeça, pelos ouidos, pescosso, the ospeitos, oqual anci... pedio Socorro a $d^{+}$Snrā e as Almas, emilagrozamente sarou as $\mathrm{d}^{\mathrm{as}}$ feridas. Aos 17 de ${ }_{8} \mathrm{br}^{\circ}$ de 1743." 37

b. "Milagre que $\mathbf{S}$. Vicente Ferrer ... ....Antonio Pinto que hindo a acolher-se para casa quasi a noite o seguirão dois ... na caza lhe correrão ... facadas com facas de ... para o por morto e pegarlha no anno de 1757." 38

c. "M" $\ddot{\mathrm{q}}$ fez $\mathrm{NSr}^{\mathrm{c}}$ do Carmo a Joze Alves de Cardo $\ddot{\mathrm{q}}$ indo denoute pela ponte do Roz desta $V^{\natural}$ lhederaó hua facada pelo peito de q. esteve amorte asistido de dois Cirugiois, eapegandoce com $\mathrm{M}^{\text {ta }}$ fé com a Virgem $\mathrm{Sr}^{-7}$ do Carmo teve Saude pref Anno de 1765." 39

interessante notar em a a descrição pormenorizada do caso, o emprego de vocábulos de uso popular - p. ex. perdigoto - os erros de ortografia, as diversas abreviaturas (também em c), a escrita de novembro - „br - em a, etc. Com esses escritos pode-se, sem dúvida, conhecer um pouco da linguagem popular da época.

Agora quatro ex-votos de escravos. A legenda de letra $f$, mesmo não tendo referência verbal quanto à classe social do ofertante, pertence a um ex-voto que traz na pintura a representação de uma mulher negra deitada na cama.

d. "M $\overline{\mathbf{q}}$ fes a $\mathbf{S . S . ~ A n n a ~ a h u ̃ ~ p r e t o ~ L u i s ~ e s c r a v o ~ d e ~ L u i s ~}$ $\operatorname{Pr}^{2} \tilde{q}$ quebrando huã perna pela colxa e sendo emcanada 3 vezes sem denēhuã soldar lheabrio osyrurgiaó aperna eserrandolhe as pontas dosōssos por entercessaõ da milagroza $S$. sevio sam em 20 de $8 b r^{\circ}$ de 1732 annos." 40 
e. "M. Q. FES ASNR" S. ANA AIOAO ESCRAVO DE AN"" DIAS GODIM $\mathbf{Q}$. SEACHAVAGRAM ENFERMO EIA SEM ESPERANCAS DEVIDA ERECORENDO OSNR. DOD? ESCRAVO AMILAGROZA SNR" LOGO SEACHOU COMSAUDE NO ANNODE 1758." 41

f. "Milagre que fes o Sñr Bom Jezus a Tiadozia da Costa $\overline{\bar{q}}$ estando grave $m^{\text {'e }}$ enferma com huma doença perigoza apegouce com fe viva com o di Sñr. logo ... deparou saude ficando livre da molestia 1798." 42

g. "Mce $\bar{q}$ fez N. Sra do Carmo a Jozefa Pinta de Souza escrava de Inocencio Pinto de Souza $q$ estando $\mathrm{M}^{\circ}$ mal de hũ் froxo de sangue deitando alguas Mollas edes confiando da $d^{a}$ os Surigiois adei... raō eella com $M^{1 a}$ ffêe se apegou côm N. Sr $^{\wedge} q^{\lambda}$. alivrou de molestia $q^{\lambda}$ padeçia Março de 1759 annos." 43

Esse tipo de ex-voto pode servir de documento e elemento de estudo das relações sociais no periodo colonial. Em d e e temos, por exemplo, o nome do escravo acompanhado do nome de seu dono. As vezes, quem recorria ao santo era o próprio dono, como podemos ver em e - "ERECORENDO OSNŘ. DOD ESCRAVO...". Em g o sobrenome da escrava é o mesmo do dono, mudando apenas o gênero do primeiro sobrenome... Já em d e e os escravos não têm sobrenome.

Confrontemos agora esses ex-votos de escravos com o de um padre, representante de uma classe mais ilustrada na estrutura da sociedade colonial:

h. "Desta sorte fas patente o $\mathrm{Pa}^{\circ}$ Joze Montairo, grande prodigio $q$ em seu favor obrou a $S^{9}$ Anna livrando 0 ... no Dia 18 de Abril do Anno de 1725." 44

Vejamos agora algumas legendas de tábuas votivas nas quais mães e pais agradecem pela cura de seus filhos: 
i. "Milagre que fez Santa Efigenia ao menino Matheus que estando com uma molestia grave ja desenganado, sua mãe apegou-se com a dita santa, logo teve alivio e recobrou a saude

\section{Anno de 1756"45}

j. "Milagre $\tilde{\mathbf{q}}$. fes a Sra. S'a Anna a Fran. "a inocente, $\tilde{q}$. estando perigoza $\mathrm{m}^{\text {te }}$ inferma, sem esperansas devida: apegouce com ad" $\mathrm{Snr}$. logo diclinou saude ficando livre e inteira $\mathrm{m}^{\text {te }} \mathrm{sam}$. 1798." 46

1. "Milagre que fês o Sr. Bom Jezus de Mattosinhos, a João inocente, $q$ estando perigosamente $p^{2}$ morrer de hua infermidade, apegou-se a Mãy com o ... foi patente o seu milagre e logo ficou livre." (séc. XVIII) ${ }^{47}$

m. "Milagre que fez Nosa $\operatorname{Srn}^{a}$ da Nazarê afilha duAnaro ... e Izabel Per de Jesus dehumagrande enfermide que teve eemplorando ao Patrocinio da $d^{y}$ senhora obaỹ eamay da $\mathrm{d}^{\mathfrak{a}}$ menina ficou logo amenina sam como couza que senão tivesse nada." (séc. XVIII ou início do XIX) ${ }^{48}$

Por fim, alguns ex-votos oferecidos por mulheres. interessante notar que estas tábuas votivas tornam-se. assim, num dos únicos documentos à respeito de mulheres e escritos pelas mesmas, na sociedade colonial mineira do século XVIII. Todas as legendas referem-se a enfermidades ocorridas com as ofertantes:

n. "Milagre q fes ors de Matozinhos a Anna. Tereza $\vec{q}$. estando gravem ${ }^{\text {te }}$ emferma dehum tumor na perna apegandoce com o so rs. logo ficou milhor do que promesso por a publico o milagre do 'S. no anno 1770." 49

o. "Mercê que fez $\mathbb{N}^{\text {" }} \mathrm{S}^{\mathfrak{a}}$ das Dores a Francisca de Barros, que estando gravemente enferma, de uma ferida na cabeça, que the sobreveio, que chegou a estar sem falla muitos dias e dezenganada por professores (medicos) em que não era possivel escapar, se apegou com $N^{*} S^{4}$ das Dores logo teve melhoras ficando sem senão algum; anno de 1775." 60 
p. “M. q. Fes o Sr DoMatoz", ARita Anglea, da Costa estando de parto conacriansa morta noventre oitodias a 14 ddezbro, e botou a 22 do mesmo mes em o anno d1781" 61

q. "M. q. fes S. Luiz Rey de Frea a Izabel Maria de Jezus, em 24 de jan. do anno de $1782 . " 52$

r. "M. Q. F. O Senhor de MattoZinhos, a Maria Angelica da Conceissão, que estando com hum froxo de Sangue semter mais esperança devida epegando-se Comod' $\mathbf{S} r$ no Fin deoito dias logo cobrou milhoras em 23 de Junho 1787." 63

s. "Milagre $\mathrm{q}$ fes o $\mathrm{Sn}^{r}$ bom Jezus a Silveria Maria da Conceisão $q$ estando $\mathrm{m}^{\text {to }}$ mal de hum mordidela de hum Bixo ... nos beisos pegandose com o d" $\mathrm{S}^{\mathrm{r}}$ logo teve saude" (séc. XVIII ou início do XIX) ${ }^{54}$

\section{CONCLUSAOO}

a. O ex-voto pintado mineiro fez parte de um arsenal cultural trazido até nós pelo colonizador português. Foi, assim, transplantado ao Brasil e a Minas Gerais. Conservando algumas características do ex-voto português, sofreu em nosso meio certas modificações como, por exemplo, quanto aos temas, escrita e classe social dos ofertantes. Torna-se necessário, porém, um estudo mais profundo antes de chegarmos a uma conclusão definitiva sobre o assunto.

b. Essas pequenas tábuas votivas mineiras são obras primas da arte popular religiosa setecentista e devem ser consideradas como tal. Faz-se necessária a preservação dessas peças em locais que facilitem a pesquisa, o estudo e a contemplação pública.

c. O ex-voto mineiro constitui preciosa fonte de informaçōes sobre a nossa cultura do século XVIII. Cabe lembrar aqui as palavras do mestre Luís da Câmara Cascudo ${ }^{65}$ sobre o ex-voto: "O "Ex-voto" é uma voz informadora da cultura coletiva, no tempo e no espaço, tão legítima e preciosa como uma parafernália arqueológica. Vale muito mais do que uma coleção de crâneos, com suas respectivas e graves medições classificadoras. E um dos mais im- 
pressionantes e autênticos documentos da mentalidade popular, do Neolitico aos nossos dias. E sempre contemporâneos, verdadeiros e fiéis.".

d. Para quem se interessar e quiser apreciar os ex-votos mineiros do século XVIII, aqui vai uma lista de locais onde podemos encontrá-los:

- Sala de Milagres do Santuário do Bom Jesus do Matosinhos, Congonhas do Campo, MG.;

- Museu da Inconfidência, Ouro Preto, MG.;

- Museu do IPHAN, São João Del Rei, MG.;

- Museu do Diamante, Diamantina, MG.;

- Igreja Nossa Senhora do O, Sabará, MG.;

- Museu do Aleljadinho, Ouro Preto, MG.

\section{NOTAS BIBLIOGRAFICAS}

01. Cesar, Getúlio. Crendices, suas origens e classificação. Rlo de Janeiro, MEC, 1975. p. 146.

02. ARAưJo, Alceu Maynard. Folclore Nacional. 2.ed. São Paulo, Melhoramentos, 1967. v.III. p. 17.

03. BARROS, Souza. Arte, folclore, subdesenvolvimento. Rlo de Janeiro, Paralelo: INL(MEC), 1971, p. 134.

04. ROSA. Guimarảes. Sagarana. 21.ed. Rlo de Janeiro, José Olymplo, 1978. p. 254.

05. DALl'AGNOL, Raimundo. O "Ex-voto". Ars Medla, Belo Horizonte $5(240)$ : 4-5, nov. 1977.

06. FrotA, Lélia Coelho. Promessa e milagre nas representaç̃es coletivas... In.: Promessa e milagre no Santuário do Bom Jesus de Matosinhos, Congonhas do Campo, MG. Brasilia, Mec; Sphan: Pró-Memória, 1981. p. 17.

07. SILVA, Maria Augusta Machado da. Ex-votos brasileiros. Cultura, Brasllla 1 (12): 22-30, abr./jul. 1971.

08. MEIRELES, Cecilla. Artes populares. Rlo de Janelro, Fdiç̃es de Ouro, 1968. p. 142 .

09. SILVA, M. Augusta M. da. Ob. cit. 
10. OLIVEIRA, Gilka Correa de. Ex-votos. Recife, IJNPS; Centro de Estudos Folclóricos, 1976. $8 \mathrm{p}$.

11. TRIGUEIRO, Osvaldo Meira. O ex-voto, um veículo de informação popular. Ars Media, Belo Horizonte 6 (272): 6, jul. 1978.

12. Cresar, Getúlio. Ob. cit. p. 147.

13. CASTRO, Márcia de Moura. O ex-voto em Minas Gerals e suas orlgens. Cultura, Brasilla (31): 106-12, Jan./mar. 1979.

14. ROTERDAM, Erasmo de. Elogio da Loucura. Río de Janeiro, Ediçðes de Ouro, s.d. p. 94-6.

15. Oliveira, G. Correa de. Ob. cit.

16. TRIGUEIRO, Osvaldo Melra. Ob. cit.

17. SILVA. M. Augusta M. da. Ob. cit.

18. BARDI, Pletro Maria. História da Arte Braslleira. São Paulo, Melho-. ramentos, 1975. p. 163.

19. MEIRELES, Cecilla. Ob. cit. p. 139.

20. SAMPAIO, Márcio. A paisagem mineira. Belo Horizonte, Fundação Palácio das Artes, 1977. (Catálogo da exposição). p. 16.

21. LEVY, Hanna. Retratos coloniais. In.: Pintura e escultura I. FAUUSP E MEC-IPHAN, 1978. (textos escolhidos da RIPHAN, 7.) p p. 182-3.

23. FROTA, Lélla Coelho. Arte de viver e arte de fazer na Coleção Jacques Van de Beuque. In.: Arte Popular Brasileira. Museu de Arte Moderna do Rlo de Janeiro - 6 de julho a 22 de agosto de 1976. (Catálogo da exposiçăo). p p. 26-7.

24. CASTRO, M. de Moura. Ob. clt.

25. SMITH. Robert. O caráter da tábua votlva luso-brasilelra.

Colóquio/Artes, Lisboa (14): 58-62, fev. 1972.

26. In.: SMITH, Robert. Ob. clt. p. 60.

27. In.: SMITH, Robert. Ob. cit. p. 59.

28. SILVA, . Augusta M. da. Ob. cit.

29. Oltveira, G. Correa de. Ob. cit.

30. FROTA, Lélia Coelho. Ob. cit. nota 06.

31. CASTRO, M. de Moura. Ob. cit. 
32. CASTRO, M. de Moura. Ob. cit.

33. FrotA, Lélia Coelho. Ob. cit. nota 06.

34. SMITH, Robert. Ob. cit.

35. CASCUDO, Luís da Camara. Carta a Luis Beltrão sobre o "Ex-voto". Comunicação \& Problemas, Recife 1 (2): 133-5, s.d.

36. Castro, M. de Moura. Ob. cit.

37. Locallzação: Museu da Inconfídência, Ouro Preto, MG.

38. Localização: Coleção particular.

39. Locallzação: Museu do IPHAN, São Joãó Del Rey, MG.

40. Locallzação: Museu do Aleljadinho, Ouro Preto, MG.

41. Locallzação: Museu do Aleijadinho, Ouro Preto, MG.

42. Locallzação: Coleção particular.

43. Localização: Museu do IPHAN, São Joăo Del Rey, MG.

44. Locallzação: Coleção particular.

45. Locallzação: Coleção partlcular.

46. Localização: Coleção partlcular.

47. Localização: Coleção partıcular.

48. Locallzação: Coleção particular.

49. Localização: Coleção particular.

50. Localização: Museu do Aleijadinho, Ouro Preto, MG.

51. Localização: Museu do Dlamante, Diamantına, MG.

52. Locallzaçăo: Coleção particular.

53. Localização: Museu do Dlamante, Dlamantina, MG.

54. Localização: Coleção particular.

55. CASCUDO, Luís da Câmara: Ob. clt. 